\title{
The Effect of Dynamic Balance Performance on Lower Extremity Injury in Division III Football Players
}

\author{
Brian J. Coulombe, DAT, LAT, ATC ${ }^{1}$; Cameron J. Powden, PhD, LAT, ATC 2 \\ 'Texas Lutheran University, Seguin, TX; ${ }^{2}$ Indiana State University, Terre Haute, IN
}

\begin{abstract}
Identifying and implementing evidence based prevention programs present a significant challenge for athletic trainers. Despite encouraging results in research, individual interventions are often specific to a setting or population and dependent on identifying accurate injury risk factors. This practice-based research is an attempt to apply current evidence in prevention to a population of division three football athletes. The clinical staff reviewed national and site-specific injury data and identified lower extremity (LE) injury as the area of focus. Evidence was searched to identify modifiable risk factors and valid measurement tools that could be addressed in our setting. Dynamic balance has been well documented as a risk factor for LE injury and the $Y$ balance test (YBT) has been shown to be an accurate measure of balance and increased risk of injury. The purpose of our investigation was to determine if our population exhibited similar injury rates in those with balance deficits as documented in other settings. We chose the football program within our setting due to the high number of athletes and consistent injuries that occur throughout the season. All returning football athletes were measured for dynamic balance using the YBT during the annual screening process. Injury record keeping through electronic medical record (EMR) system was consistent with current procedures and noncontact LE injuries were analyzed to remove non-modifiable risk factors. Comparisons were made between YBT results and incidence of injury in $46 \%$ of our athletes. Statistical analysis revealed no relationship between YBT measurements and LE injury. Our results are contradictory to those reported in recent studies from differing populations. Implementation difficulties and population differences are theorized reasons for our inability to achieve similar results. Clinically, our results underscore the need for clinicians to measure interventions within their own settings to determine usefulness and make the best decision for their patients.
\end{abstract}

Key Phrases

Injury Risk Reduction, Injury Surveillance, Prevention

\section{Correspondence}

Dr. Brian Columbe, Texas Lutheran University, 1000 W. Court Street, Seguin, TX 78155

E-Mail: bcoulombe@tlu.edu

Twitter: @BCoulATC

\section{Full Citation}

Columbe BJ, Powden CJ. The effect of dynamic balance performance on lower extremity injury in division III football players. Clin Pract Athl Train. 2018;1(1):15-20.

https://doi.org/10.31622/2018/0001.4

Submitted: May 3, 2018 Accepted: May 25, 2018

\section{INTRODUCTION}

A thletic trainers are tasked with implementing policies and procedures designed to prevent or mitigate emergent, acute, or chronic injuries and medical conditions ${ }^{1}$. Prevention of injuries before they occur (primary prevention), providing early identification and care (secondary prevention) to limit the extent of an injury, and comprehensive rehabilitation (tertiary prevention) after an injury are all areas in which athletic trainers work to prevent the disabling effects of injury. Interventions to prevent injury have historically focused on the individual and specific risk factors to which patients are exposed. ${ }^{2}$ To maximize primary and secondary prevention interventions it is important that athletic trainers focus their efforts on evidence-based initiatives aimed at specific populations of patients. ${ }^{2}$

Football is a collision sport that has the highest injury rates of all NCAA intercollegiate athletic programs. ${ }^{3}$ Injuries to the lower extremity (LE) make up $54 \%$ of all injuries. Furthermore, the knee $(12 \%)$, ankle (11.8\%), and thigh musculature $(10.7 \%)$ are the top 3 body parts injured in practice activities. ${ }^{3}$ One specific institution, a private, liberal arts, NCAA Division III University, has experienced similar injury rates for these types of LE injuries. Examination of electronic medical records (EMR) from the previous academic year revealed $57 \%$ of LE injuries at the specific institution were the result of non-contact mechanisms. In an effort to improve healthcare services provided to our athletic population, the clinical athletic training staff searched recent evidence to identify modifiable risk factors for LE injury. Our evidence-based approach also included identifying a LE injury prevention program that had been evaluated for feasibility.

Postural control and dynamic balance are two modifiable risk factors that have been related to LE injury.4,5 Recent evidence indicates that 
impaired balance increases an athlete's risk of injury. 6-10 Furthermore, prophylactic balance training programs have demonstrated the ability to decrease injury risk. $5,11,12$ Together these findings highlight the importance of identifying balance deficits during the prevention process. Single leg balance tests, like the Star Excursion Balance Test (SEBT) and the newer Y-Balance Test (YBT), are frequently used tools in lab-based and practical research studies that use single leg reach distance to evaluate dynamic balance and postural control.4-7,13-15 Evidence for using the YBT as an injury prediction tool has been encouraging with multiple studies identifying anterior reach asymmetries of over $4 \mathrm{~cm}$ and composite scores of under $89.9 \%$ as strong predictors of injury. $7,8,11,15$

As our clinical staff reviewed current evidence on the YBT, concerns of replicating results found in previous studies within our own patient population became evident. It was important for us to establish measures at which our athletes experience increased injury before implementing interventions to prevent those injuries. We determined that our first step in improving quality of care in the area of injury prevention started with the collection and analysis of data within a specified population to determine what, if any, interventions may be appropriate. Although the YBT has performed well as a predictive measure of injury in NCAA Division 1 football, basketball, and soccer athletes, its utility to identify at-risk individuals is unclear within the football population at the specific NCAA Division III institution. The purpose of this practice-based research project was to determine the relationship between the YBT and LE injury in football athletes at the institution. Our hypothesis was that those experiencing non-contact LE injuries would demonstrate significantly greater asymmetries and lower composite scores than the uninjured population.

\section{PATIENTS}

One hundred thirty-nine football student-athletes from the same NCAA Division III institution participated in this screening and monitoring program. Prior to the start of the 2016 football season, all athletes completed an annual medical screening process of which YBT measurements were included. Athletes were given brief information on the purpose of balance assessment

Copyright (C) by Indiana State University as a means to identify risk of LE injury before completing measurements. Athletes with a LE injury at the time of YBT evaluation were excluded from this study. Athletes who were included in this study were then monitored throughout the competitive season for LE injuries.

\section{INTERVENTION}

The FMS Y Balance Test (Perform Better, West Warwick, RI) was used to measure balance in athletes. The YBT tool consists of a center platform and three PVC pipes attached in anterior, posteromedial, and posterolateral directions. Each directional pipe is labeled in centimeters $(\mathrm{cm})$ and includes a sliding block that an athlete pushes as they reach in a specific direction (Figure 1). Reliability assessments of YBT measurements in multiple studies suggest strong intrarater reliability between ICC $=0.85-0.93$ and interrater reliability between $I C C=0.91-1.0 .5,8,15$ The measurement protocol utilized was based on a previous protocol. ${ }^{15}$ Athletes were instructed to stand barefoot on the center platform and reach out in each direction, with the contralateral limb, to slide a block down the directional pipe. Trials were repeated if athletes removed hands from hips, failed to return to the start, threw the block, or placed excess weight on the block. Athletes completed four practice trials followed by three measurement trials in each direction. The furthest reach in each direction was recorded, normalized to leg length and used for analysis. Two examiners monitored the trials to ensure correct procedure and two others recorded reach distances. YBT examiners completed educational sessions to ensure that those measuring YBT understood the process and could obtain reliable measurements. Leg length was measured following YBT. Leg length was measured from the anterior superior iliac spine to the distal tip of the medial malleolus on both limbs after athletes lifted their hips off of the table and returning to a supine position. All YBT and leg length measurements were completed by the clinical athletic training staff $(<8$ years BOC certified) or senior level professional athletic training students who completed a training module with measurement practice at the institution. The information was stored in a Microsoft ${ }^{\circledR}$ Excel spreadsheet to be analyzed with injury data to determine the, if any, relationship exists between balance and LE injury. This was an important first 
step in determining the necessity of possible prevention programming.

\section{OUTCOME MEASURES}

Injury EMR surveillance occurred via SportsWare ${ }^{\circledR}$ (Computer Sports Medicine Inc. Stoughton, MA.) database and lasted the entire fall 2017 season. Injuries to the LE that resulted from any non-contact mechanism were included if the event required medical care and resulted in time-loss of one or more days of normal football activities. A report was generated through the EMR for the stated conditions and YBT values for those injured were matched in Microsoft ${ }^{\circledR}$ Excel database for analysis. Athletes sustaining multiple injuries were included for their first injury only.

Analyses were conducted using a statistical software program (IBM Corp. Released 2015. IBM SPSS Statistics for Windows, Version 23.0. Armonk, NY: IBM Corp). Means and standard deviations were calculated for all reach distances and asymmetries in each leg for injured and uninjured athletes. Limb asymmetries were calculated by taking the absolute difference between limbs for each reach direction and composite score. Receiver operator characteristic (ROC) curves were created to establish a cut-off point at which a difference in scores correlated with an increased chance of LE injury. This was done for each reach and composite score asymmetry to determine risk of injury in this population. The $P$ value was set at $P<0.05$ a priori.

\section{RESULTS}

Non-contact LE injuries occurred in 62 of 136 athletes who completed the 2017 football season (Table 1). The normalized reach distances and composite scores are presented in Table 2 for injured and uninjured athletes. Non-significant asymmetries (Table 3 ) were noted among injured and uninjured populations $(P=0.382)$ with mean asymmetries for each direction and composite being within 1\% except for the posteromedial reach direction (2\%). ROC data failed to reach significance in establishing cut off points for reach or composite score asymmetries.
Table 1. Sustaining Non-Contact LE Injuries.

\begin{tabular}{lcc}
\hline & Number & Percentage \\
\hline No Injury & 74 & 54.4 \\
Injury & 62 & 45.6 \\
Total & 136 & 100.0 \\
\hline
\end{tabular}

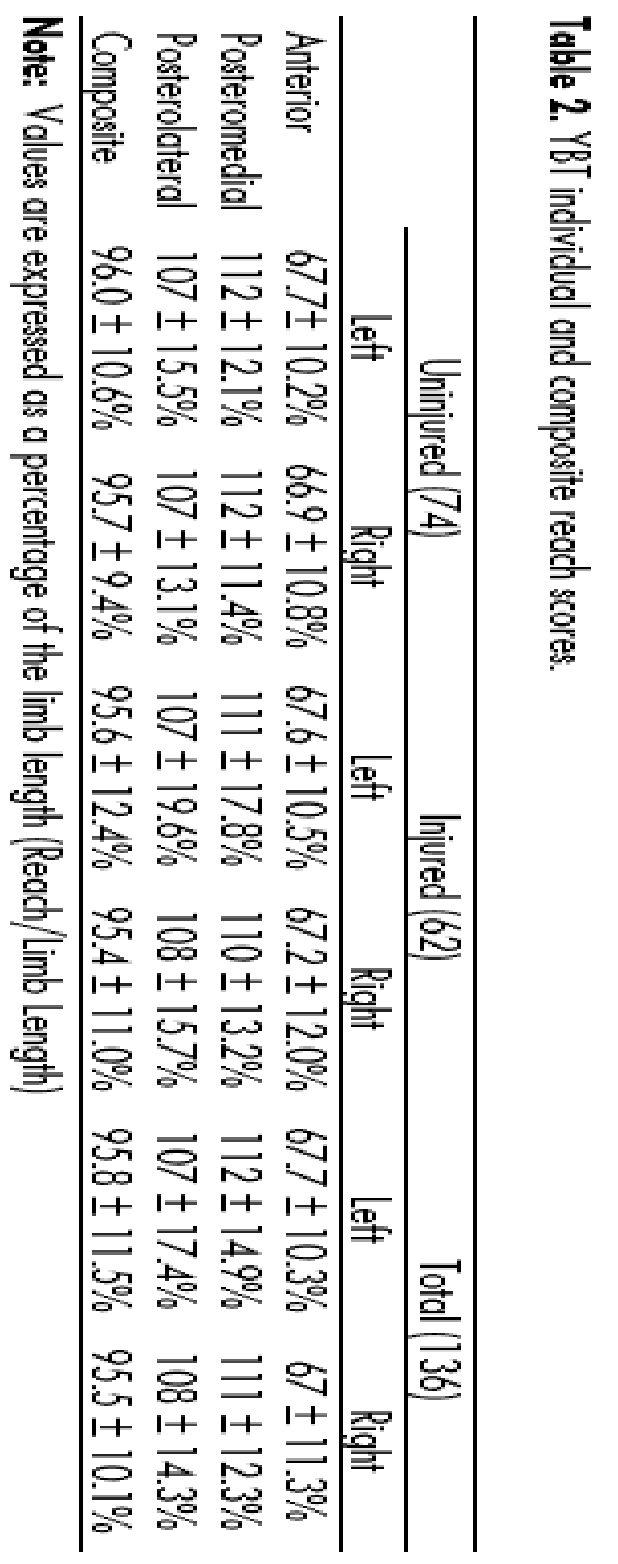


Table 3. YBT Asymmetry Values for each direction

\begin{tabular}{lcccc}
\hline Group (n) & Anterior & Posteromedial & Posterolateral & Composite \\
\hline Uninjured (74) & $5.8 \pm 4.8 \%$ & $7.5 \pm 6.7 \%$ & $9.1 \pm 7.4 \%$ & $4.3 \pm 4.2 \%$ \\
Injured (62) & $6.4 \pm 5.6 \%$ & $9.5 \pm 14.1 \%$ & $9.0 \pm 11.7 \%$ & $5.2 \pm 6.2 \%$ \\
Average (136) & $6.1 \pm 5.2 \%$ & $8.4 \pm 10.8 \%$ & $9.1 \pm 9.6 \%$ & $4.7 \pm 5.2 \%$
\end{tabular}

Note: Values are expressed as a percentage difference between limbs

Table 4. Receiver Operator Characteristic Findings

\begin{tabular}{lcccccc}
\hline $\begin{array}{l}\text { Asymmetry } \\
\text { Measure }\end{array}$ & Area & Std. Error & $P$ value & $\begin{array}{c}\text { Cut Off } \\
\text { Score }\end{array}$ & Sensitivity & Specificity \\
\hline Anterior & .519 & .050 & .702 & $0.1 \%$ & $61.3 \%$ & $47.3 \%$ \\
Posteromedial & .532 & .050 & .526 & $7.2 \%$ & $43.5 \%$ & $67.6 \%$ \\
Posterolateral & .456 & .050 & .382 & $1.0 \%$ & $98.0 \%$ & $11.0 \%$ \\
Composite & .513 & .051 & .800 & $8.4 \%$ & $19.4 \%$ & $91.9 \%$ \\
\hline
\end{tabular}

\section{DISCUSSION}

The purpose of this study was to determine if a relationship exists between YBT performance and the incidence of LE injury in NCAA Division III football players. Our results did not find any YBT reach direction that was predictive of LE injury. This is in contrast to recent investigations of YBT performance in other populations. Using the star excursion balance test (SEBT), Plisky ${ }^{6}$ found that high school basketball players with anterior reach asymmetries greater than $4 \mathrm{~cm}$ demonstrated a 2.5 times greater injury risk. Additionally, female athletes were 6.5 times more likely to sustain injury if their composite reach score was less than $94 \%$ of their limb length. ${ }^{6}$ The relation of anterior reach asymmetry to increased injury risk was corroborated using the YBT in a population of NCAA Division 1 athletes from various sports in a 2015 investigation by Smith et al. which found that participants with anterior reach differences of over $4 \mathrm{~cm}$ were almost 4 times more likely to sustain a LE during their competitive season. ${ }^{9}$ Similar YBT procedures have been applied among amateur and professional soccer players finding a $4 \mathrm{~cm}$ difference in the posteromedial direction as a risk factor for injury. ${ }^{16}$ In contrast, another investigation using the YBT among NCAA Division I football players was unable to corroborate injury risk in those with anterior reach

Copyright (C) by Indiana State University All rights reserved. ISSN Online 2577-8188 asymmetries, but did find a 3.5 times higher injury rate in those with composite scores of less than $89 \%$ of limb length. 8 The combination of these findings highlight the variation in the predictive ability of the YBT/SEBT and underscores the importance of continued investigations within multiple populations. Before adopting quality improvement interventions, athletic trainers should incorporate evidence from their own patient population along with current research evidence to ensure the usefulness of those interventions. Practice-based research and analysis of such data can help focus efforts on the needs of our patients and improve overall outcomes. Despite our results, the YBT can still be a useful marker of neuromuscular control in patients after specific injuries. Investigations among patients with lateral ankle sprains, chronic ankle instability, anterior cruciate injury, and patellofemoral pain syndrome consistently exhibit significant reach deficits in the directions used in the YBT. ${ }^{4}$ Additionally, rehabilitation focusing on improving balance while reaching in anterior, posteromedial, posterolateral directions has shown improvement within injured populations. ${ }^{4}$ One such study among those with chronic ankle instability found significant improvement in reach distances after 4 weeks of balance exercise focused on the anterior, posteromedial, and posterolateral directions. ${ }^{10}$ Within our application, baseline 
measurements were used as objective return to play criteria for those injured throughout the season. Evidence has established the YBT as an appropriate measure of dynamic postural control, and that interventions focusing on balance and neuromuscular control exercises lead to improved reach scores. ${ }^{17-20}$

There were a number of challenges experienced in the implementation of the YBT testing procedures, which may have affected measurements collected. A large number of football athletes (139) reported for the preparticipation exam that was scheduled for a 3hour time period. The addition of a balance testing station increased the time required to complete all components of the exam, which created a sense of fatigue in athletes and clinicians. The YBT was a new procedure for staff and professional level students who were conducting measurements. Training and practice sessions were employed, but unforeseen challenges during a time-sensitive exam may have compromised the ability to record accurate measurements. Additionally, returning players may not have provided maximal effort as this was a new and unexpected task that was seen as a burden. Lessons learned through unsuccessful experiences provide valuable information on how to improve procedures and must be addressed in future investigations of the YBT as a predictive assessment of injury. Educational sessions for athletes and coaching stakeholders can lead to buy-in and commitment to gathering accurate measurements. Further training and experience among those conducting measurements will increase efficiency and accuracy of the measurement process. Finally, procedures to limit the number of athletes measured in one session may help with the impatience of athletes and the fatigue of clinicians.

The results of this practice-based research did not identify YBT measurements predictive of lower extremity injury. Adjustments to implementation policies will be necessary if the YBT will be continued to be used as a predictor of lower extremity injury or an objective rehabilitation measure. One of the benefits that resulted from our investigation was an additional clinical outcome measure to assess return to activity status for those that incur lower extremity injury. Comparisons to YBT baseline measures of dynamic balance will be useful information to assist clinical decision making regardless of injury predictive ability.

\section{CLINICAL APPLICATION}

While identifying and using current evidence to guide clinical practice is an important function of an athletic trainer, implementation of specific interventions designed to prevent injury should be tailored to the individual setting and population being treated. Practice based research provides information on potential usefulness of interventions and can provide additional clinician-rated outcomes to improve clinical decision-making. Continuous data collection and assessment of interventions is crucial for clinicians to make the best decisions for their patients.

\section{REFERENCES}

1. Henderson J. The 2015 Athletic Trainer Practice Analysis Study. Omaha, NE: Board of Certification; 2015. http://www.bocatc.org/system/document_v ersions/versions/24/original/boc-pa7content-outline20170612.pdf?1497279231. Access Date: May 1, 2018.

2. Hoffman $M$, Bovbjerg $V$, Hannigan $K$, et al. Athletic training and public health summit. $J$ Athl Train. 2016;51(7):576-580. https://doi.org/10.4085/1062-605051.6.01

3. Dick R, Ferrara MS, Agel J, et al. Descriptive epidemiology of collegiate men's football injuries: National Collegiate Athletic Association Injury Surveillance System, 19881989 through 2003-2004. J Athl Train. 2007;42(2):221-233.

4. Gribble PA, Hertel J, Plisky P. Using the Star Excursion Balance Test to assess dynamic postural-control deficits and outcomes in lower extremity injury: a literature and systematic review. J Athl Train. 2012;47(3):339-357. https://doi.org/10.4085/1062-605047.3.08

5. Shaffer SW, Teyhen DS, Lorenson CL, et al. Ybalance test: a reliability study involving multiple raters. Mil Med. $2013 ; 178(11): 1264-1270$.

\footnotetext{
Clinical Practice in Athletic Training
} Volume 1 - Issue 1 - June 2018 
https://doi.org/10.7205/MILMED-D-13-

\section{2}

6. Plisky PJ, Rauh MJ, Kaminski TW, Underwood FB. Star Excursion Balance Test as a predictor of lower extremity injury in high school basketball players. J Orthop Sports Phys Ther. 2006;36(12):911-919. https://doi.org/10.2519/iospt.2006.2244

7. Trojian TH, McKeag DB. Single leg balance test to identify risk of ankle sprains. $\mathrm{Br}$ J Sports Med. $\quad 2006 ; 40(7): 610-613$. https://doi.org/10.1136/bjsm.2005.02435 $\underline{6}$

8. Butler RJ, Lehr ME, Fink ML, Kiesel KB, Plisky PJ. Dynamic balance performance and noncontact lower Eextremity injury in college football players: An initial study. Sports Health: A Multidisciplinary Approach. 2013;5(5):417-422.

https://doi.org/10.1177/1941738113498 703

9. Smith CA, Chimera NJ, Warren M. Association of $y$ balance test reach asymmetry and injury in division I athletes. Med Sci Sport. Exerc. 2015;47(1):136-141.

https://doi.org/10.1249/MSS.0000000000 000380

10. McKeon $P$, Ingersoll $C$, Kerrigan DC, Saliba $E$, Bennett $B$, Hertel J. Balance training improves function and postural control in those with chronic ankle instability. Med Sci Sports Exerc. 2008;40(10): 1810 .

https://doi.org/10.1249/MSS.0b013e3181 7e0f92

11. McGuine TA, Greene JJ, Best T, Leverson G. Balance as a predictor of ankle injuries in high school basketball players. Clin J Sport Med. 2000;10(4):239-244.

12. Emery CA, Rose MS, McAllister JR, Meeuwisse $\mathrm{WH}$. A prevention strategy to reduce the incidence of injury in high school basketball: $A$ cluster randomized controlled trial. Clin J Sport Med. 2007;17(1):17-24. https://doi.org/10.1097/JSM.0b013e3180 2e9c05

13. Herrington L, Hatcher J, Hatcher A, McNicholas M. A comparison of Star Excursion Balance Test reach distances between $\mathrm{ACL}$ deficient patients and asymptomatic controls. Knee. 2009; 16(2):149-152. https://doi.org/10.1016/i.knee.2008.10.00 $\underline{4}$

Copyright ( $)$ by Indiana State University
14. Hertel J, Braham RA, Hale SA, OlmstedKramer LC. Simplifying the star excursion balance test: Analyses of subjects with and without chronic ankle instability. J Orthop Sports Phys Ther. 2006;36(3):131-137. https://doi.org/10.2519/iospt.2006.36.3.1 31

15. Plisky PJ, Gorman PP, Butler RJ, Kiesel KB, Underwood FB, Elkins $B$. The reliability of an instrumented device for measuring components of the star excursion balance test. N Am J Sports Phys Ther. 2009;4(2):92.

16. Gonell AC, Romero JAP, Soler LM. Relationship between the $Y$ balance test scores and soft tissue injury incidence in a soccer team. Int J Sports Phys Ther. $2015 ; 10(7): 955$.

17. Leavey VJ, Sandrey MA, Dahmer G. Comparative effects of 6-week balance, gluteus medius strength, and combined programs on dynamic postural control. J Sport Rehabil. 2010;19(3):268-287. https://doi.org/10.1123/isr.19.3.268

18. McLeod TCV, Armstrong T, Miller M, Savers $\mathrm{JL}$. Balance improvements in female high school basketball players after a 6-week neuromuscular-training program. J Sport Rehabil. 2009;18(4):465-481. https://doi.org/10.1123/isr.18.4.465

19. Fitzgerald D, Trakarnratanakul N, Smyth B, Caulfield B. Effects of a wobble board-based therapeutic exergaming system for balance training on dynamic postural stability and intrinsic motivation levels. J Orthop Sports Phys Ther. $\quad 2010 ; 40(1): 11-19$. https://doi.org/10.2519/iospt.2010.3121

20. Filipa A, Byrnes R, Paterno MV, Myer GD, Hewett TE. Neuromuscular training improves performance on the star excursion balance test in young female athletes. $J$ Orthop Sports Phys Ther. 2010;40(9):551-558. https://doi.org/10.2519/iospt.2010.3325 